\title{
La influencia jesuita en la conformación de la Liga Comunista 23 de Septiembre durante la década de los setentas del siglo XX en México*
}

\section{Resumen}

Este trabajo analiza el papel que desempeñaron los sacerdotes jesuitas en la politización de sectores estudiantiles regiomontanos durante la década de los sesentas y setentas del siglo XX en México. El enfoque parte de un estudio de caso de corte cualitativo. Los instrumentos que se utilizaron fueron la investigación documental de archivos judiciales y entrevistas. Como resultado de este trabajo se señala que los jesuitas incentivaron la movilización estudiantil y tuvieron un impacto considerable que permitió establecer vínculos entre estudiantes católicos y militantes de la Juventud Comunista, quienes ante la represión del régimen autoritario mexicano decidieron adoptar planteamientos más radicales como la autodefensa armada. La investigación permite concluir que a pesar de que el grupo de jesuitas no se incorporó a la lucha armada, uno de sus discípulos, Ignacio Salas Obregón, llegaría a conformar una de las organizaciones de guerrilla urbana más importantes del país la Liga Comunista 23 de Septiembre.

\section{Palabras clave}

Tesauro: religión, política, movimiento estudiantil.

Autor: Liga Comunista 23 de Septiembre, Compañía de Jesús, teología de la liberación, inteligencia estatal.

Referencia para citar este artículo: Torres Martínez, Héctor Daniel. "La influencia jesuita en la conformación de la Liga Comunista 23 de Septiembre durante la década de los setentas en México". Anuario de Historia Regional y de las Fronteras 23.2 (2018): 141-172.

Héctor Daniel Torres Martínez: doctorante del Centro Universitario de Ciencias Sociales y Humanidades, Universidad de Guadalajara, México. Magíster en Historia de México por el Colegio de San Luis, A.C., México. Licenciado en Historia por la Universidad Autónoma de Nuevo León (UANL), México. Código ORCID: https://orcid.org/0000-0002-7747-0241. Correo electrónico: hector.dairn02@gmail.com.

\footnotetext{
"Este trabajo forma parte de mi tesis de maestría en Historia de México titulada "Monterrey Rebelde 19701973. Un estudio sobre la Guerrilla Urbana, la sedición armada y sus representaciones colectivas", San Luis Potosí: Colegio de San Luis. A.C., 2014, la cual fue posible y contó con apoyo del Centro Consejo Nacional de Ciencia y Tecnología (CONACYT).
} 


\title{
The Jesuits Influence in the Creation and Shaping of the Communist League September 23 During the Seventies of $20^{\text {th }}$ century in Mexico
}

\begin{abstract}
This article analyzes the role played by Jesuit priests in the politicization of Monterrey student sectors during the 1960s and 1970s in Mexico. The approach is based on a qualitative case study. Documentary research of court records and interviews were used as instruments to accomplish this. As a result of this research, it pointed out that Jesuits encouraged student mobilization and had a considerable impact that made it possible to establish links between Catholic students and members of the Communist Youth who, faced with the repression of the Mexican authoritarian regime, decided to adopt more radical approaches such as armed self-defense. This research allows us to conclude that, despite the fact that the group of Jesuits did not join the armed conflict, one of their disciples, Ignacio Salas Obregón, would come to form one of the most important urban guerrilla organizations in the country, the Communist League September 23.
\end{abstract}

Keywords

Thesaurus: Religion, Politics, Student movement.

Author's keywords: Communist League September 23, Society of Jesus, Theology of Liberation, State intelligence.

\section{A influência jesuíta na conformação da Liga Comunista 23 de setembro durante a década de setenta do século XX no México}

\section{Resumo}

O presente artigo analisa o papel desempenhado pelos padres jesuitas na politização dos setores estudantis de Monterrey durante a década dos anos sessenta e setenta do século XX no México. O enfoque se baseia em um caso de estudo de tipo qualitativo. Os instrumentos que se utilizaram foram a pesquisa documental de arquivos judiciais e as entrevistas. Como resultado deste trabalho, destaca-se que os jesuitas incentivaram a mobilização estudantil e tiveram um impacto considerável que permitiu estabelecer ligações entre estudantes católicos e estudantes militantes da Juventude Comunista que decidiu adotar posições mais radicais como a autodefesa armada em face à repressão do regime o autoritário mexicano. A investigação permite concluir que apesar de que o grupo de jesuitas não se incorporou à luta armada, um de seus discípulos, Ignacio Salas Obregón, chegaria a conformar uma das organizações de guerrilha urbana mais importantes do pais, a Liga Comunista 23 de Setembro.

Palavra- chaves

Thesaurus: religião, politica, movimento estudantil.

Palavras-chaves do autor: Liga Comunista 23 de Setembro, Companhia de Jesús, teología da libertação, inteligência estatal. 


\section{Introducción}

Este trabajo busca repensar los vínculos y confluencias que se generaron entre religión y política durante la segunda mitad del siglo XX a partir de considerar la participación de jóvenes católicos en la Liga Comunista 23 de Septiembre (LC23S) una de las organizaciones de guerrilla urbana más importante en México. Ponderar una singular experiencia guerrillera permitirá, a partir de un estudio de caso, develar elementos para comprender el proceso bidireccional de politización de lo religioso y de religiosidad en lo político que experimentaron los actores sociales quienes formaron parte del proceso armado. La convergencia, unión y coincidencia de ambas perspectivas ayudará a examinar la forma en que el capital simbólico de la religión fue apropiado y resignificado por expresiones políticas de izquierda. Las investigaciones que existen en México acerca de la actuación de católicos en el movimiento armado por lo regular son escazas, fragmentarias y muy generales. Uno de los primeros abordajes corresponde al trabajo de Óscar Flores, "Del Movimiento Universitario a la guerrilla. El caso de Monterrey 1968-1973" el cual se limita a señalar, de manera muy breve, "el perfil de la guerrilla urbana en monterrey". También existen artículos de investigación periodística como los de la revista Proceso, "El caso del fundador de la Liga 23 de Septiembre ante la Fiscalía Especial". ${ }^{2}$ El artículo es interesante ya que menciona aspectos importantes de la vida de Ignacio Salas Obregón ${ }^{3}$ a partir de entrevistas con familiares y personas que lo conocieron en su etapa previa a su ingreso en la clandestinidad. Otros trabajos como el de Fortino Domínguez, "Católicos en la guerrilla Mexicana de los sesentas. El caso de la Liga Comunista 23 de Septiembre" 4 analizan el papel que desempeñaron dos estudiantes en el entorno regiomontano que, influidos por sacerdotes jesuitas, llegaron a ocupar posiciones importantes, a nivel de dirigencia, en esta agrupación guerrillera: Ignacio Salas Obregón e Ignacio Olivares Torres con el objetivo de examinar cuáles fueron los elementos que pudieron influir para que decidieran optar por esta perspectiva radical y las motivaciones que subyacían en esta determinación, al igual que tratar de comprender qué los impulsó a

\footnotetext{
${ }^{1}$ Menciona que para el caso del grupo guerrillero Los Procesos, ellos “atrajeron hacia sí a un potente grupo de intelectuales de influencia cristiana jesuita, militantes de la teoría de la liberación. Este grupo cristiano jesuita estaba integrado por estudiantes de la UANL y del ITESM". Óscar Flores, "Del Movimiento Universitario a la Guerrilla. El caso de Monterrey 1968-1973”, Movimientos armados en México en el siglo $X X$, v. II. eds. Verónica Oikión y Marta García (Morelia: Centro de Investigación y Estudios Superiores en Antropología Social/El Colegio de Michoacán, 2006) 475- 477.

2 Pascal Beltrán del Río, "El caso del fundador de la Liga 23 de Septiembre, ante la Fiscalía Especial" Proceso, 1320. (2002).

${ }^{3}$ La información del reportaje periodístico con base en testimonios orales menciona que "Nació en Aguascalientes, el 19 de julio de 1948, en el seno de una familia de comerciantes, Ignacio fue el segundo de los cuatro hijos del matrimonio de Salvador Salas Calvillo y Enriqueta Obregón Urtaza. Educado en colegios católicos, Ignacio tuvo una infancia tranquila, con no pocos privilegios. Fines de semana en el Country Club, clases de pintura y vacaciones en Acapulco y Manzanillo eran parte de la rutina familiar, recuerda Luz Eugenia, su hermana. Aunque los Salas Obregón eran muy devotos — don Salvador llegó a estar en un seminario, en Sonora, y Salvador, el hijo mayor de la familia, es sacerdote-, el interés de Ignacio por la religión no despuntó hasta que sus padres lo enviaron a Monterrey, para estudiar la preparatoria y la carrera de ingeniero civil en el Tecnológico". Beltrán, "El caso" 25.

${ }^{4}$ Fortino Domínguez Rueda, "Católicos en la guerrilla mexicana de los setenta. El caso de la Liga Comunista 23 de Septiembre” (Tesis, Licenciatura en Historia, Universidad de Guadalajara, 2006).
} 
tomar las armas. Por último, el estudio de Ana Lucía Álvarez Gutiérrez, "De Católico a Guerrillero: el caso de Ignacio Salas Obregón ${ }^{5}$ examina el proceso de radicalización del líder y fundador de la LC23S. La periodización que traza la autora toma como punto de inicio el año de 1964, cuando Ignacio entró en contacto con las corrientes progresistas del catolicismo, a 1971, año en que abandonó la vida pública y se sumó al proyecto clandestino.

En gran medida las fuentes con las que se ha abordado el tema de la participación de los jóvenes católicos en el movimiento armado socialista de la década de los setentas del siglo XX han sido principalmente bibliográficas, hemerográficas y destaca particularmente la historia oral que ha adquirido mucha relevancia para la recuperación de testimonios sobre este fenómeno social. Sin embargo, es un tema que no se ha explorado a profundidad. La investigación que se presenta, en primer lugar, toma en consideración la influencia familiar católica de los actores involucrados en este trabajo que los acompañó desde la infancia hasta la juventud. A partir de ahí se busca analizar ¿Cuál fue el papel que jugaron los sacerdotes jesuitas en el proceso de politización de sectores estudiantiles en el entorno regiomontano? La cuestión es relevante en tanto que algunos de los jóvenes que estudiaron con los padres ignacianos eventualmente pasaron a integrar la militancia armada de Liga Comunista 23 de Septiembre.

Para ello se ha tomado como elementos de reconstrucción histórica principalmente expedientes judiciales resguardados en el Archivo General de la Nación (AGN) y que fueron generados por la Dirección Federal de Seguridad (DFS) y Dirección de Investigaciones Políticas y Sociales (DIPS). Al ser fuentes oficiales posibilitan entrever y analizar algunos de los movimientos tanto de estudiantes universitarios como de los sacerdotes jesuitas en la ciudad de Monterrey. Sin embargo, la información que contienen estos documentos fue realizada a partir de reportes policiacos (en algunos casos contradictorios). Incluso algunos de ellos exageran la peligrosidad de los guerrilleros o las actividades que ellos denominaban "subversivas" por parte de los padres ignacianos. Evidentemente tales "huellas" contienen estigmas y estereotipos (la visión de los encargados de la represión) que comúnmente las autoridades aplicaban indistintamente a cualquier "sedicioso". De igual manera las declaraciones de los detenidos por la DFS tienen sus limitantes. La información contenida en muchas ocasiones fue redactada por las mismas corporaciones policiacas con datos que había sido arrancada bajo torturas o bien era llenada con referencias que ya poseían y se le obligaba al acusado a firmarlas. Pretender que este tipo de testimonios tenga un fin "neutro" es imposible, el contenido de los mismos explícitamente se orientaba fundamentalmente a exponer claramente la "conducta delictiva" de los personajes que no siempre servía para garantizar su estadía en la cárcel. ${ }^{6}$ Sin embargo esta clase de documentación a partir del 2012 ha experimentado un proceso de censura institucional, motivo por el cual la consulta de los acervos respectivos se ha limitado

\footnotetext{
${ }^{5}$ Ana Lucía Álvarez Gutiérrez, "De Católico a Guerrillero: el caso de Ignacio Salas Obregón (Tesis, Licenciatura en Historia, Universidad de Guanajuato, 2015).

${ }^{6}$ Existen casos como los de Ignacio Salas Obregón (Los Procesos/LC23S), Salvador Corral (Los Macías), Ignacio Olivares (LC23S), Arturo Vives Chapa (Las Fuerzas de Liberación Nacional), entre cientos, quienes fueron capturados por la DFS, rindieron su declaración pero fueron asesinados cuando no desaparecidos.
} 
considerablemente. No obstante, en la medida de lo posible se ha complementado la información con testimonios orales y escritos de los actores aludidos en esta historia para generar una visión más completa sobre el fenómeno social.

\section{Sacerdotes y revolución en el plano latinoamericano}

Un fenómeno característico en América Latina durante la segunda mitad del siglo XX fue la irrupción de distintas experiencias guerrilleras. ${ }^{7}$ Para los modernos insurrectos un acontecimiento que impactó en los distintos movimientos armados fue el triunfo de la Revolución cubana, el 1 de enero de 1959, que abrió una nueva concepción política y que representó un cuestionamiento a los postulados del comunismo internacional que planteaba llegar al socialismo a través de la dirección del Partido Comunista. La victoria del movimiento armado cubano fue una ruptura histórica y tuvo un impacto sin precedentes en la época contemporánea, convirtiéndose en un signo, programa y esperanza para todo el continente. ${ }^{8}$ No obstante un mecanismo para contener la onda expansiva revolucionaria estribó en generar un estereotipo sobre movimiento guerrillero y su accionar que desplegaba estigmas con una fuerte carga peyorativa:

Pesaba más el estereotipo de la violencia guerrillera, al suponer que toda acción política violenta o revolucionaria contra el gobierno y/o el Estado era sinónimo de acción guerrillera o terrorismo y que toda acción guerrillera o terrorista era producto de una infiltración y conspiración extranjera [...] Esta visión simplista, $[\ldots]$ puede ser filiada como un subproducto ideológico de la Guerra Fría $[\ldots]$ La guerrilla sería, así, convertida en metáfora y símbolo comunista. ${ }^{9}$

Por tanto, la temible "conjura internacional del comunismo" fue utilizada por múltiples gobiernos latinoamericanos para legitimar el despliegue represivo de su accionar. El "anticomunismo" se convirtió en una herramienta útil que permitía a los diversos gobiernos justificar el "combate" contra tendencias contestatarias. De tal manera que durante las décadas de los sesentas y setentas América Latina experimentó un proceso de violencia política atravesado por el establecimiento de distintos regímenes militares y la irrupción de movimientos guerrilleros, ambos fenómenos generaron una escalada de violencia en mutua confrontación.

Sin embargo, la inserción y participación de sacerdotes católicos en movimientos revolucionarios y organizaciones político-militares fue considerable y muy significativa. En esta tesitura, el ejemplo paradigmático de la vinculación entre religión y política radical lo representó el sacerdote guerrillero colombiano, Camilo

\footnotetext{
${ }^{7}$ Gabriel Gaspar, Guerrillas en América Latina (Chile: FLACSO, 1997) 5.

${ }^{8}$ Raúl Vidales, "Periodización de la historia de la Iglesia en México (1968-1983)", La participación de los cristianos en el proceso popular de liberación en México, coord. Pablo Casanova (México: Siglo XXI, 1986) 47.

9 Ricardo Melgar Bao, "La memoria sumergida. Martirologio y sacralización de la violencia en las guerrillas latinoamericanas", Movimientos armados en México en el siglo XX, v. I, eds. Verónica Oikión y Marta García (Morelia: Centro de Investigación y Estudios Superiores en Antropología Social/El Colegio de Michoacán, 2006) 37.
} 
Torres quien se incorporó al Ejército Nacional de Liberación (ELN) el 19 de octubre de 1965. La decisión de asumir la vía armada "introdujo el tema de la legitimidad de la violencia popular para los cristianos". ${ }^{10}$ Además, para el cura bogotano la decisión de sumarse al grupo armado estaba cimentada en ideas cristianas como la "guerra justa" o la insurrección contra la tiranía. Por lo cual, de acuerdo con Darío Martínez Morales sería impreciso:

[...] atribuir, [...] al marxismo y a su tesis de la lucha de clases, la culpabilidad de la violencia revolucionaria cristiana. Si bien es cierto que en la doctrina marxista la violencia opera como motor de la historia y de las transformaciones sociales, no es menos cierto que la tradición cristiana contiene y da curso en algunos momentos a la justificación de la violencia guerrera. Lo que contribuye a determinar el caso particular de Camilo, no es la [...] justificación de la violencia por doctrinas extrañas al cristianismo, sino que más bien, dicha justificación se encuentra en el corazón mismo de la tradición cristiana. ${ }^{11}$

No obstante, tras su muerte el 15 de febrero de 1966 en un enfrentamiento con el ejército colombiano, Camilo Torres llegaría a ser “[...] un ícono de la izquierda católica en América Latina por su convicción de que la revolución era un imperativo cristiano y por el ejemplo que dio tomando armas y muriendo como guerrillero". ${ }^{2}$ Pero no fue el único, otro caso representativo fue el del clérigo jesuita Fernando Hoyos quien llegó a Guatemala en 1972 y posteriormente se incorporó al Ejército Guerrillero de los Pobres (EGP). En Brasil, el "acercamiento de sectores católicos hacia la izquierda fue evidente en el grupo de sacerdotes dominicanos que se incorporaron a la organización revolucionaria liderada por Carlos Marighella, la Acción Libertadora Nacional. ${ }^{13}$ El Salvador, por su parte, fue un país que experimentó una de las guerras civiles más radicales del entorno. Un caso que ilustra la violencia contra los clérigos ocurrió el 16 de noviembre de 1989 en donde fueron asesinados seis jesuitas por el ejército salvadoreño al interior de las instalaciones de la Universidad Centroamericana José Simeón Cañas. ${ }^{14}$

Para poder comprender estos acontecimientos permeados por acciones radicales y la justificación de la violencia por parte de sacerdotes es fundamental considerar el contexto histórico por el que atravesó la Iglesia católica durante la segunda mitad del siglo XX. De acuerdo con Nercesian, la cuestión radicaba en que "[...] la Iglesia se adaptase a la nueva coyuntura histórica que requería destacar el valor comunitario y humanista que debía tener la práctica religiosa y que a su vez, contribuyó al

\footnotetext{
${ }^{10}$ Horacio Crespo, "Una hermenéutica comprensiva de la radicalización cristiana en los sesenta", Cristianismo y Revolución. Los orígenes intelectuales de la guerrilla argentina, Gustavo Morello (Argentina: Universidad católica de Córdoba, 2003).

${ }^{11}$ Darío Martínez Morales, "Camilo Torres Restrepo: cristianismo y violencia”, Theologica Xaveriana 61. 171 (2011): 161

${ }^{12}$ Daniel Levine, “Camilo Torres: fe, política y violencia”, Sociedad y Religión 21. 34/35 (2011): 59.

${ }^{13}$ Inés Nercesian, La política en armas y las armas de la política: Brasil, Chile y Uruguay 1950-1979 (Buenos Aires: CLACSO, 2013) 86.

${ }^{14}$ Juan Antonio Monroy, Un enfoque evangélico a la Teología de la Liberación (Barcelona: Libros Clie, 1991) 99.
} 
acercamiento de algunos sectores del catolicismo hacia el socialismo". ${ }^{15}$ La variable explicativa central de esta aproximación apunta a los cambios que se generaron a raíz de Concilio Ecuménico del Vaticano II (1962-1965) convocado por el papa Juan XXII que "representó el hecho religioso y teológico más importante del pasado siglo". ${ }^{16}$ En sintonía con estas trasformaciones en la Iglesia católica, el papa Pablo VI publicó la encíclica Populorum Progressio el 26 de marzo de 1967 que:

Se inscribe en la línea de los grandes documentos que, a partir de la Rerum novarum (1891), de León XIII, desarrollaron la doctrina social de la Iglesia católica. Constituye una llamada urgente y vigorosa, a favor del desarrollo integral del hombre y de la humanidad. [Sin embargo] La recepción de la encíclica desató problemas de violencia, incluso se llegó a divulgar que el Papa animaba a la subversión violenta, que algunos interpretaron como un deber cristiano. En algunos sectores se leyó la encíclica, presentándola como apoyo de la revolución. ${ }^{17}$

La encíclica papal generó importantes cambios en el catolicismo nivel mundial. No obstante, para América Latina en 1968 ocurrieron dos acontecimientos sumamente relevantes y que tuvieron gran impacto entre los católicos del continente. El primero de ellos fue la publicación en mayo de la Carta a los Jesuitas de América Latina, (también conocida como Carta de Río por ser Río de Janeiro, Brasil, el lugar en la que se redactó) escrita por el General de los jesuitas, Pedro Arrupe. Este documento señalaba que "para orientar nuestros ministerios de acuerdo con las necesidades humanas y religiosas más urgentes de nuestro continente, nos proponemos, primero, desplazar una parte de nuestras fuerzas apostólicas hacia la masa innumerable y creciente de los abandonados". ${ }^{18}$ Para la Compañía de Jesús, el Concilio del Vaticano II inició una renovación de su modo de vida religioso y una "decidida apertura al mundo presente, una pasión por el mundo moderno y por el anuncio de la fe desde las preocupaciones de los hombres de su tiempo". ${ }^{19}$ El segundo suceso, de considerable trascendencia, se llevó a cabo en Medellín, Colombia del 26 de agosto al 6 de septiembre de 1968, durante la II Conferencia General del Episcopado Latinoamericano. Para algunos autores se trató de "una suerte de adaptación del Concilio Vaticano II para América Latina", ${ }^{20}$ en conjunción con la encíclica Populorum Progressio, en la cual se llamaba a los cristianos a comprometerse con los sufrimientos de sus pueblos. ${ }^{21} \mathrm{Un}$ componente que se desprende de las discusiones anteriores fue la llamada Teología de

\footnotetext{
${ }^{15}$ Inés Nercesian 85.

16 Josep-Ignasi Saranyana, Cien años de Teología en América Latina, 1899-2001 (Bogotá: Consejo Episcopal Latinoamericano, 2005) 87.

${ }^{17}$ Josep-Ignasi Saranyana 90-92.

18 "Carta de los provinciales de América Latina a los jesuitas del continente", Jesuitas. Anuario de la Compañia de Jesús 1968-69, 77. Citado en Alberto Gutiérrez, "Arrupe y América Latina”, Pedro Arrupe, General de la Compañia de Jesús. Nuevas aportaciones a su biografía, ed. Gianni la Bella (España: Mensajero y Sal Terrae, 2007) 411.

${ }^{19}$ José Sols, La teología histórica de Ignacio Ellacuría (Madrid: Trotta, 1999) 32.

${ }^{20}$ Inés Nercesian 85.

${ }^{21}$ Hernán Brieza, Camilo Torres. Sacristán de la Guerrilla (Buenos Aires: Capital Intelectual, 2007) 23.
} 
la Liberación que “[...] supone la compasión por la dramática situación de miseria en la que vive la mayor parte del pueblo, la indignación ética ante el hecho y un nuevo encuentro espiritual con Jesucristo en la historia a través de los pobres al confrontar el Evangelio con la vida y acción sobre todo social". ${ }^{22}$ Además este acontecimiento fue un punto clave para el clero latinoamericano que posibilitó una profunda reflexión acerca del papel y la postura de la Iglesia ante situaciones muy concretas por las que atravesaba la región como la pobreza y las injusticias sociales al igual que las acciones que debían llevar a cabo los católicos para combatirla. Una de ellas, estribó en la decisión que tomaron algunos sacerdotes de incorporarse como militantes de organizaciones guerrilleras. De acuerdo con la interpretación de Saranyana, los clérigos emprendieron el camino de las armas "impresionados quizá por la injusticia social y la corrupción, pensaron que la situación de extrema pobreza y de continuada represión legitimaba el recurso a las armas, y que, de ese modo, se contribuiría al advenimiento de Cristo". ${ }^{23}$

Para el caso de México, Roberto Blancarte señala que “[...] del concilio surgió una Iglesia mexicana que no era ni la tradicionalista ultraconservadora ni la reformista radical, aunque algunos de sus miembros se inclinasen por estas tendencias". ${ }^{24} \mathrm{De}$ acuerdo con la versión de Víctor Muro, se generaron “[...] visiones polarizadas [...] por un lado se manifestaron los grupos tradicionalistas que, ante la 'amenaza comunista' dentro de la Iglesia, tuvieron desplantes violentos, y por el otro, los grupos que pugnaban por establecer un compromiso social en su línea pastoral". ${ }^{25}$ A continuación se analiza el papel que desarrolló un grupo de sacerdotes jesuitas de orientación progresista en la ciudad de Monterrey durante la década de los sesentas y setentas del siglo XX cuyo compromiso e implementación de los lineamientos conciliares y de Medellín acerca de la intervención de la Iglesia en cuestiones sociales los convertirían en un potente factor de movilización social dentro del estudiantado regiomontano.

\section{La presencia jesuita y la agitación estudiantil en Monterrey}

El Instituto Tecnológico de Estudios Superiores (ITESM) abrió sus puertas en 1943. La institución representa un paradigma de la acción de la industria regiomontana en el campo de la educación superior. Nació por la iniciativa de Eugenio Garza Sada y un grupo de empresarios mexicanos entre los que se destacan predominantemente industriales. ${ }^{26}$ Para este grupo empresarial era fundamental contar " $[\ldots]$ con personas capacitadas técnica y profesionalmente para hacer frente a los requerimientos de la

\footnotetext{
${ }^{22}$ Miguel Concha, "Teología de la Liberación”, Diccionario de Politica, t. II, Norberto Bobbio et al (México: siglo XXI, 1999) 1157.

${ }^{23}$ Josep-Ignasi Saranyana 89.

${ }^{24}$ Roberto Blancarte, Historia de la Iglesia católica en México (México: Fondo de Cultura Económica, 1992), 208.

${ }^{25}$ Víctor Gabriel Muro, Iglesia y movimientos sociales (México: Colegio de Michoacán, 1994) 103.

${ }^{26}$ Rodrigo Mendirichaga, El Tecnológico de Monterrey, (México: Castillo, 1982) 37.
} 
reciente industrialización y bonanza económica" 27 por las que atravesaba la ciudad de Monterrey y el estado de Nuevo León. ${ }^{28}$ Durante la segunda mitad del siglo XX, para el caso regiomontano de acuerdo con la investigación de Patricio Solís, el papel que adquirió el acceso a una educación profesional fue muy importante:

[...] no sólo como un valor instrumental para una eventual movilidad ocupacional, sino como un mecanismo de ascenso social [...] La enseñanza universitaria, representaba una oportunidad para ingresar a nuevos mundos a través de la cultura, pero también había adquirido una mayor trascendencia en el mundo laboral producto de la creciente demanda de trabajadores capacitados ligada a la expansión industrial. ${ }^{29}$

Por consiguiente la oferta educativa que priorizó el ITESM desde su inicio se enfocó en las áreas de "Ingeniera Industrial, Estudios Contables y Preparatoria [...] consideró que al mismo tiempo que se desarrollaran las ingenierías en concordancia con el crecimiento industrial de Nuevo León y específicamente Monterrey, también habría un importante desarrollo de empresas comerciales y bancarias". ${ }^{30}$ Lo que tenía de especial el Tecnológico de Monterrey, de acuerdo con Rodrigo Mendirichaga "era su condición de ser fundada por la iniciativa privada, con la ideología propia de ese sector social; en ese momento histórico con un claro matiz católico". ${ }^{31}$ Por tanto, desde su fundación, el ITESM procuró contar con sacerdotes jesuitas quienes además de impartir clases "fungieron como guías espirituales de los alumnos que vivían en las residencias de la institución." 32 Sin embargo según el testimonio de Horacio Gómez Junco, (director de estudios del ITESM en 1968) a los clérigos ignacianos se les estipularon algunas condiciones: "[...] que no vinieran más de tres sacerdotes, que no vivieran dentro del internado, que no tuvieran cargos administrativos y que solamente actuaran como profesores auxiliares". ${ }^{33}$ Aunque investigaciones recientes han señalado que no se seguían al pie de la letra. ${ }^{34}$

\footnotetext{
${ }^{27}$ María de los Dolores García Piera, "Surgimiento y expansión del Instituto Tecnológico y de Estudios Superiores de Monterrey” (Tesis, Maestría en Historia, Universidad Iberoamericana, 2008) 29.

${ }^{28}$ Desde finales del siglo XIX e inicios del siglo XX, la capital del Estado de Nuevo León comenzó a despuntar como un bastión industrial y financiero de considerable relevancia en México. Dos elementos que permitieron perfilar a la ciudad de Monterrey hacia un proceso de industrialización y urbanización fueron la creación de la Cervecería Cuauhtémoc en 1890 (que llegaría a ser propiedad de Eugenio Garza Sada) y la Compañía Fundidora de Fierro y Acero en 1900, primera de Latinoamérica. Javier Rojas y María Elena Rodríguez, "La industria siderúrgica en Monterrey HyLSA (1943-1985)", Monterrey siete estudios contemporáneos, ed. Mario Cerutti (México: UANL, 1988) 57.

${ }^{29}$ Patricio Solís, Inequidad y movilidad social en Monterrey (México: Colegio de México, 2007) 84-85.

${ }^{30}$ Dolores García 74.

${ }^{31}$ Mendirichaga 38-39.

${ }^{32}$ Dolores García 73.

${ }^{33}$ Horacio Gómez Junco, Desde Adentro (Monterrey: Gobierno del Estado de Nuevo León, 1997) 120. Citado en Lucía Álvarez 59.

${ }^{34}$ Lucía Álvarez señala que "[...] los jesuitas no seguían al pie de la letra las instrucciones que Eugenio Garza Sada, o el grupo de los industriales, mandaba y contaban con cierta independencia". Para ello la investigadora refiere las memorias de Herman Von Bertrab quien llegó al ITESM en 1963 y fue profesor de tiempo completo. Este jesuita menciona que había más sacerdotes que los tres requeridos por Eugenio Garza Sada: "Por esos años el Superior de la comunidad era el jesuita Pablo López Lara y estaba integrada
} 
No obstante, a inicios de la década de los sesentas se integraron al ITESM algunos jesuitas progresistas influidos por la Teología de la Liberación quienes "[...] a la luz del Concilio Vaticano II, promovieron la formación de Centros de Información y Acción Social". ${ }^{35}$ Los informes de inteligencia mexicana señalan al respecto que estos sacerdotes estaban de acuerdo con "la nueva línea mesiánica de la 'JUSTA VIOLENCIA". Mencionan además que "[...] los principales promotores de esta situación, son los jesuitas Salvador Rábago y Xavier de Obeso, [...] que están de acuerdo en que utilicen la justa violencia, los oprimidos, que se ven obligados a recurrir a la misma para lograr su liberación". Incluso el mismo documento afirma que los jesuitas "llegaron con una consigna a Monterrey dirigida por el máximo jerarca de su orden, el padre Carlos Arrupe: tratar de experimentar un cambio social que se expresaba en el abismo que media entre pobres y ricos." 36 Sin embargo a pesar de ser un reporte de investigación policial, que si bien exagera la postura de los clérigos hacia violencia justificada ya que ninguno de ellos asumió o participó en el movimiento armado, la información acerca de la consigna parece ser plausible en tanto que de acuerdo con Dolores García "a partir de 1966 por orden de la dirigencia de la Compañía, se hizo un llamado a sus miembros a realizar cambios estructurales en la orientación de su apostolado". ${ }^{37}$ Cabe mencionar que para 1965 a pesar del considerable desarrollo industrial que había adquirido Monterrey (y que la había posicionado como una de las tres principales ciudades de México) "todavía el 67\% del total de la población se encontraba en condición de pobreza". ${ }^{38}$ Incluso tanto la distribución del ingreso y el bienestar en el área metropolitana de Monterrey, a partir de este momento, experimentó una curva descendente que se tornó más desigual en décadas posteriores. ${ }^{39}$

Por último, un dato interesante en el mismo informe refiere que antes de la aparición de los curas progresistas "los clérigos adoctrinaban a los estudiantes en principios sociales cristianos, se les hablaba de pecado y matrimonio; tras la incorporación de los jesuitas, la directriz de la explicación de la doctrina cristiana cambió radicalmente [...] los jóvenes eran adoctrinados en una mentalidad progresista dentro del ramo del

por Manuel Uribe, Salvador Rábago, y Xavier de Obeso, cinco jesuitas en total”. Von Bertrab 134. Citado en Lucía Álvarez 60.

${ }^{35}$ Dolores García 91.

${ }^{36}$ Archivo General de la Nación, (AGN), Dirección de Investigaciones Políticas y Sociales (en adelante DIPS), Caja: 0478, Legajo: 1, 660-662, (30 de enero de 1969).

${ }^{37} \mathrm{La}$ autora presenta como evidencia la "Información tomada de los puntos 1 y 2 de la Introducción al Decreto de la Congregación General 32 dado a conocer bajo la dirigencia del padre Pedro Arrupe S.J., el cual señala que la misión de la Compañía de Jesús hoy es el servicio de la fe, del que la promoción de la justicia constituye una exigencia absoluta, en cuanto forma parte de la reconciliación de los hombres exigida por la reconciliación de ellos mismos con Dios”. Dolores García 91.

${ }^{38}$ Menno Vellinga, "Crecimiento económico y distribución del ingreso en Monterrey", Monterrey siete estudios contemporáneos, ed. Mario Cerutti (México: UANL, 1988) 31.

${ }^{39}$ De acuerdo con Andrés Montemayor esta situación se manifestó en los salarios en tanto que “[...] para 1966 la percepción salarial familiar en 'la Sultana del Norte' era de \$12,352 mensuales, incluso más alto que el ingreso promedio familiar del país que era de $\$ 11,278$; sin embargo esto no propiciaba la movilidad social o reducía los índices de marginalidad”. Andrés Montemayor Hernández, Historia de Monterrey (México: Asociación de Editores y Libreros de Monterrey, 1971) 436. 
cristianismo". ${ }^{40}$ Esta información es plausible en tanto que la línea de acción de estos sacerdotes estaba en correspondencia con los diálogos e inquietudes latinoamericanas. Al respecto Héctor Viejo menciona que:

[...] en julio del 68 se realiza en Paraguay [un seminario de asesores] en el que participa además de la asociación Nacional de México, dos asesores de Monterrey, Raúl Rábago y de Obeso y el asesor de Toluca [de tal manera que] las preguntas sobre ¿Cuál es la postura del estudiante católico en un mundo secularizado? y ¿Qué significa Dios en un mundo adulto? Fueron reemplazadas por interrogantes que calaban más profundamente en la realidad Latinoamericana como ¿Cuál es el papel de un estudiante católico en un mundo injusto socioeconómicamente? o ¿Qué significa ser católico en el tercer mundo? ${ }^{41}$

Estas cuestiones y problemáticas, si bien no figuran dentro de los planes de estudio, fueron proyectadas en los estudiantes del ITESM a través de diversas conferencias y seminarios. Por ello, los sectores estudiantiles del tecnológico experimentaron un proceso de politización proyectado desde el plano religioso, por lo cual aquellos desmovilizados estudiantes de las universidades privadas comenzaron a involucrarse en problemáticas sociales del momento. Un componente interesante, que también habría que considerar ya que ayuda a explicar la aceptación de estos sacerdotes entre los estudiantes del tecnológico estriba en el aspecto generacional pues "además de su perfil de educadores, los jesuitas que vivían en Monterrey eran en su mayoría jóvenes, lo cual los llevó a entablar relaciones de contemporaneidad e igualdad con los alumnos". ${ }^{42}$ De acuerdo con un testimonio de uno de estos jesuitas, señala que:

[...] establecí relación amistosa con muchos de mis alumnos. Ellos eran mi familia. Vivía entre ellos más tiempo que el resto de los maestros. No era sólo un profesor de economía. Era jesuita y entendía mi vocación no como la sacramental ni la de Padre Espiritual que da consejos con orientación moral y religiosa. Vivía con ellos, tomaba café con ellos, conversaba en mi oficina con ellos sobre todos los temas imaginables [...] y sobre otros que me interesaban a mí y deseaba aprendieran a saborear. No pretendía insistir en que practicaran la religión, no les daba clase de catecismo, pero sí hablaba sobre problemas religiosos cuando la ocasión se presentaba. ${ }^{43}$

De igual manera, el mismo testimonio permite conocer aspectos relevantes sobre las personalidades de los sacerdotes Xavier de Obeso y Salvador Rábago, jesuitas progresistas y maestros del Tecnológico. ${ }^{44}$ Acerca del primero, Herman Von Bertrab señala que era:

\footnotetext{
${ }^{40}$ AGN, DIPS, Caja: 0478, Legajo: 1, 660-662, (30 de enero de 1969).

${ }^{41}$ Entrevista de Héctor Viejo a Lucía Álvarez, Nuevo León, México, 19 de junio de 2014.

${ }^{42}$ Lucía Álvarez 60.

${ }^{43}$ Von Bertrab 136. Citado en Lucía Álvarez 60.

${ }^{44}$ Instituto Tecnológico de Estudios Superiores de Monterrey, Boletín de Información 1966-1968: 12.
} 
De muy buen parecer, de figura atlética y fácil sonrisa. En el deporte se entregaba a ganar. Era amigable y tenía una gran cantidad de admiradoras femeninas y seguidores masculinos. Su inteligencia era práctica. Cogía el momento sin percibir las repercusiones de su acción. No era un intelectual aunque después de tantos años de formación tenía un sustento bastante sólido. Era un líder nato y tenía una innata capacidad para encontrar la expresión brillante que animara a sus oyentes y al menos para una audiencia ya entusiasmada que les aclarara caminos y enseñara sendas. Su voz granulosa y elegante sabía imponer las inflexiones adecuadas a sus palabras, a sus frases. Era idealista. Un gran corazón sincero y arriesgado que no se ponía a medir condiciones ni consecuencias. Los problemas que nos habían de sobrevenir lo radicalizaron, pero nunca lo amargaron. Su idealismo llegó finalmente a tener una coloratura utópica. Nunca fue sin embargo un fanático anguloso con el que no pudiera tratar. ${ }^{45}$

Con respecto a la personalidad Salvador Rábago, Von Bertrab lo recuerda como un hombre que:

[...] rumiaba en soledad pensamientos siempre profundos, desligados muchas veces de la realidad circundante que veía a través de lentes contemplativos [...] Ranchero de los Altos de Jalisco, poseía la entereza y la fortaleza de esa gente. Su historia personal había estado marcada por el hecho de que de niño había padecido una enfermedad en los ojos - una especie de conjuntivitis grave y crónica - que lo hizo vivir encerrado por años en una habitación oscura librado a todo un mundo interno de pensamientos y reflexión. No podía dejar de convertirse en un filósofo que le daba vuelta a las ideas no en el abstracto del pensamiento puro, pero sí en la irrealidad lejana y profunda de un corazón noble y soñador. Era altamente persuasivo con su comunicación preferentemente en grupos pequeños donde llegaba hasta lo íntimo de quienes lo escuchaban. Su dedicación, su sinceridad, su capacidad de expresión auténtica, generaban lealtad sincera en los grupos que escuchaba su mensaje. ${ }^{46}$

No obstante, la incorporación de sacerdotes jesuitas progresistas como guías espirituales y asesores del estudiantado del ITESM tuvieron profundas repercusiones. Pronto llegaron a convertirse en importantes agentes de movilización social que incentivaron la actividad estudiantil en la ciudad de Monterrey como se verá a continuación. Durante la década de los sesentas los clérigos ignacianos Xavier de Obeso y Salvador Rábago fueron asesores del Movimiento Estudiantil Profesional (MEP). Dicho organismo fue una de las ramas de Acción Católica Mexicana que, desde sus inicios, en la década de 1940, se había posicionado en el ala conservadora del catolicismo pero que a mediados de los sesentas, de acuerdo con Lucía Álvarez "cambió sus inclinaciones metodológicas y de objetivos hacia la reflexión social desde el presente a la luz de la fe". ${ }^{47}$

\footnotetext{
${ }^{45}$ Von Bertrab 141. Citado en Lucía Álvarez 71.

${ }^{46}$ Von Bertrab 142. Citado en Lucía Álvarez 72.

${ }^{47}$ Lucía Álvarez 53.
} 
En este organismo convergieron tanto religiosos y laicos con un objetivo específico, formar comunidades eclesiales de base, apoyar movimientos populares y participar en el debate cristiano-marxista. ${ }^{48}$ En un primer momento el trabajo desarrollado por el MEP, que tenía su campo de acción entre colonos de la ciudad de Monterrey, propició la convergencia y establecimiento de lazos ente las comunidades estudiantiles clericales con grupos de jóvenes comunistas. ${ }^{49}$ Uno de los personajes que participó activamente en el MEP fue Ignacio Salas Obregón quien incluso llegó a ser presidente nacional de esta organización, motivo por el cual decidió abandonar sus estudios en el ITESM. Esta determinación de acuerdo con la revista Proceso conllevó un conflicto con su padre quien "le retiró toda ayuda económica, molesto por su decisión".50 Sin embargo la influencia que recibió Ignacio Salas de los jesuitas durante su adolescencia puede rastrearse en el periodo de 1964-1968 durante el cual asistía, al igual que muchos estudiantes del Instituto a seminarios impartidos por los jesuitas. En ellos se les hablaba sobre una nueva concepción de la religión y de la necesidad de intervención de la Iglesia en los problemas sociales. ${ }^{51}$ Posteriormente a inicios de la década de 1970, Salas Obregón se dedicaría a realizar labores sociales con ellos. Según el testimonio del jesuita Héctor Viejo, por esa época una de las cuestiones de mayor relevancia era "cómo el cristiano puede, católico, cuál es el papel dentro de la universidad. Evidentemente que no es nada más ir a misa, tiene una responsabilidad con la comunidad tiene una manera de trabajar, entonces por allí es distinto". ${ }^{52} \mathrm{El}$ mismo testimonio además señala además la forma en que trabajaba el MEP:

Fundamentalmente funcionábamos con pequeñas células, con reuniones, coordinación esencial, había un grupo base en cada escuela ¿Dónde funcionábamos? no en las Iglesias, sino hay veces en el café hay veces en el patio de la escuela, y casi siempre tomábamos el método que habíamos heredado de la Juventud Obrera Católica el ver, juzgar y actual, es decir analizábamos un hecho a la luz de la fe, a la luz de todo, de la actuación de Jesús y a la luz de los documentos ¿Qué es lo que te dice este hecho? Y de allí sacábamos compromisos, o sea, yo creo que los muchachos y los asesores no teníamos ninguna duda de que estábamos haciendo una obra de Iglesia. ${ }^{53}$

De acuerdo con Juan Carlos Flores (quien después de Salas Obregón fue presidente del MEP y posteriormente, a igual que él, se uniría a la guerrilla urbana) señala que este grupo se dedicaba a: "[...] analizar la realidad. Había una metodología verjuzgar-actuar que se parecía a la de Paulo Freire ir-llegar-venir, como el MEP. Es decir, qué está pasando, cuál es el juicio católico de esto. Lo católico desde el punto

\footnotetext{
${ }^{48}$ Fiscalía Especial para Movimientos Sociales y Políticos del Pasado (FEMSPP). Borrador filtrado del Informe de la Fiscalía Especial para Movimientos Sociales y Políticos del Pasado. Vol. 7. "La guerrilla se extiende por todo el país" 433. https://nsarchive2.gwu.edu//NSAEBB/NSAEBB180/070-Grupos\%20 armados.pdf (2006).

${ }^{49}$ Barry Carr, La izquierda mexicana a través del siglo XX (México: Era, 2000) 271.

${ }^{50}$ Beltrán, "El caso" 25.

${ }^{51}$ AGN, Dirección Federal de Seguridad (en adelante DFS), Fondo: Ignacio Salas Obregón, Legajo: 4, Expediente: 11-235-73, 131, (29 de octubre de 1973).

${ }^{52}$ Entrevista de Héctor Viejo a Lucía Álvarez, Nuevo León, México, 19 de junio de 2014.

${ }^{53}$ Entrevista a Lucía Álvarez.
} 
de vista del evangelio, luego actúas. Oye esto es injusto y no mames son chingaderas y actuamos". .4

Otro de los organismos en el cual los jesuitas participaron como asesores y trabajaron activamente fue en la Organización Cultural Universitaria (OCU) denominada Obra Cultural Universitaria en los diversos reportes de investigación policial. Esta corporación fue creada por los grupos clericales de la ciudad en el año de 1962. De acuerdo con informes de la policía política estuvo financiada por Eugenio Garza Sada:

\begin{abstract}
[...] a través de un patronato para mantener a este organismo. En un primer momento contó con el absoluto respaldo del clero y del sector empresarial quienes nombraron a los jesuitas como guías para mantener la fe apostólica en los grupos estudiantiles [...] Las actividades de este grupo eran primordialmente de orientación cultural; se trataban asuntos fillosóficos, de teología y problemáticas actuales relacionados con cuestiones morales (como control de la natalidad) y desde luego la problemática universitaria.
\end{abstract}

Los reportes policiacos además consignaron que a partir del segundo informe del presidente Díaz Ordaz, "las actividades de agitación se multiplicaron, situación que fue aprovechada por los sacerdotes para dictar conferencias con opiniones en contra de las declaraciones del presidente e invitaban al estudiantado a manifestarse contra un régimen que trataba de maniatarlos". ${ }^{55}$ Uno de los espacios más interesantes que implementaron los jesuitas fue el Café Universitario. Éste ambiente propició que los miembros de la OCU (en su mayoría del ITESM) se reunieran con miembros de diferentes organizaciones estudiantiles regiomontanas al igual que militantes de la Juventud Comunista (JC). En este lugar, el 29 de julio de 1968, se despotricó en insultos contra el presidente Díaz Ordaz y ejército nacional. Las injurias contra el primer mandatario de la república, en dicho evento, llegaron a oídos de Eugenio Garza Sada, quien desautorizó la ayuda financiera y los subsidios económicos a los sacerdotes que dirigían al estudiantado en movimientos políticos en lugar de darles conferencias apostólicas. ${ }^{56}$

No obstante, uno de los primeros actos políticos, del estudiantado fue la formación de la Federación de Estudiantes del Tecnológico (FETEC). Esta organización, de acuerdo con los informes policiacos, implementó un ciclo de conferencias denominadas "Confrontación Ideológica de los Partidos Políticos de México que inició el 30 de abril de 1968". ${ }^{57}$ La dinámica del evento consistía en invitar a diversos representantes de los partidos políticos a exponer sus puntos de vista sobre el panorama político de la época y las posibilidades hacia la democracia. Este ciclo de actividades, evidentemente no fueron del agrado de la Dirección de esa Casa de Estudios. Incluso el reglamento interno prohibía la participación de sus estudiantes en cuestiones políticas. Sin embargo, al interior del campus universitario del Tecnológico, la labor de los jesuitas

\footnotetext{
${ }^{54}$ Entrevista de Juan Carlos Flores a Lucía Álvarez, Nuevo León, México, 17 de junio 2014.

${ }^{55}$ AGN, DIPS, Caja: 1501-A, Legajo: 2, 167-168, (20 de octubre de 1969).

${ }^{56}$ AGN, DFS, Fondo: Gobierno del Estado N.L., Legajo: 5, 94, (15 de abril de 1969).

${ }^{57}$ AGN, DFS, Fondo: ITESM, Legajo: 15, Expediente: 11-4-1-968, 348. (30 de abril de 1968).
} 
sobre el estudiantado se mantenía presente y su influencia se desplegó a través de una de las principales herramientas que históricamente ha utilizado la Compañía de Jesús, la representación teatral y en esta ocasión no fue la excepción. Hacia finales de diciembre de 1968 algunos estudiantes montaron una pastorela en la cual se mofaban del sistema social establecido, de los dirigentes del Tecnológico y de los principales maestros. ${ }^{58}$ De acuerdo con José Luis Sierra (uno de los participantes):

Era la ciudad de Vainilla Seca y el dueño de ella era Rico MacnGarza. En dicha ciudad había una universidad, y el rector de ésta se llamaba Fernando Papá Noel. Rico Mac -personaje que jugaba [representaba] Sierra Villarreal- dice que va a expulsar a unos estudiantes y pide los reglamentos. Le traen una carretilla con papel sanitario y después dentro de la carretilla aparece un Playboy, y me lo abren en la parte en que aparece la chica del mes. Y yo digo: ¡ay, virgencita, sácame de este apuro! Como los espectadores sólo veían las solapas, algunos gritaron: ¡muéstrenla! Entonces, la voltean y efectivamente aparece la Virgen de Guadalupe. Hicieron consejo de patronato y me corrieron por haber ofendido a la Virgen de Guadalupe. Me comunican la expulsión el primer día de clase de enero. Pero, no se imaginaron que a los pocos días se iba a organizar una huelga de hambre. ${ }^{59}$

La efervescencia estudiantil, aunada a las reacciones posteriores tras los sucesos sangrientos del 2 de octubre de 1968 en Tlatelolco, al igual que las protestas y la huelga de hambre que protagonizaron los estudiantes habían dejado la impresión en las autoridades académicas del ITESM que particularmente estos últimos movimientos los habían manipulado los sacerdotes jesuitas ${ }^{60}$ Sin embargo todos estos acontecimientos representaron no solo un distanciamiento entre el ITESM y la Compañía de Jesús, sino su ruptura. De acuerdo con la interpretación de Dolores García:

Para Garza Sada era más importante continuar con el proyecto ideológico educativo empresarial que con el humanista inspirado por los jesuitas, dado que con el primero se garantizaba la reproducción del sistema desarrollado por el Tecnológico y que era representativo de los intereses empresariales [...] Conservar a los jesuitas [...] a raíz de los cambios operados en la orientación de la Compañía, así como su injerencia en los acontecimientos ocurridos en la Institución y fuera de ella en 1968, no hubiera sido conveniente, dado que es para ese momento su proyecto [el de los jesuitas] y el de la institución en que habían laborado ya estaba en contradicción [...] la postura jesuita a favor de los oprimidos ya no era compatible con la postura empresarial de los dirigentes del Instituto. ${ }^{61}$

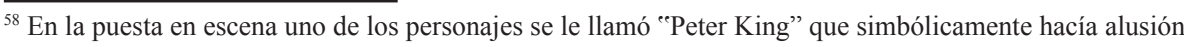
a un ex-diputado federal del Partido Acción Nacional de corte conservador y decano de los maestros, Pedro Reyes. En la obra, dicho personaje vendía sus ideas por un fajo de billetes. AGN, DIPS, Caja: 0478, Legajo: 1, 664-665, (30 de enero de 1969).

${ }^{59}$ Fernando González "Algunos grupos radicales de izquierda y de derecha con influencia católica en México (1965-1975)”. Historia y Grafía 29 (2007): 77.

${ }^{60} \mathrm{El}$ caso del sacerdote jesuita Severiano Soto, dirigente de la Congregación Mariana es ilustrativo al respecto. Este clérigo escribió un artículo en el periódico Símbolo en el cual afirmaba la necesidad de la crítica estudiantil como una vía para expresar a las autoridades del tecnológico la problemática del mismo. Rodrigo Mendirichaga 224. Citado en Dolores García 95.

${ }^{61}$ Dolores García 96.
} 
Para tratar de contrarrestar la influencia de los padres ignacianos en el estudiantado, los sacerdotes josefinos implementaron un ciclo de conferencias del 10 al 14 de marzo de 1969 para estudiantes universitarios. Las actividades tenían como objetivo primordial atacar directamente a los sacerdotes Xavier de Obeso y Manuel Rábago quienes según la orden de los josefinos:

[...] tratan de emplear una política desviada para el estudiantado con el fin de agitar en contra de las Instituciones, [...] utilizando el organismo Obra Cultural Universitaria, se han puesto de acuerdo con connotados miembros del Partido Comunista para alejar espiritualmente al joven estudiante de sus deberes apostólicos y convertirlo en un simpatizador de políticas que nada tienen que ver con la idiosincrasia de nuestro pueblo. ${ }^{62}$

Incluso algunos padres de familia protestaron enérgicamente contra la influencia de los jesuitas en sus hijos. Por ejemplo, Francisco Olvera Peralta que tras la detención de su hijo, Francisco Olvera Acevedo y un compañero suyo, Gustavo Treviño Elizondo (presidente y vicepresidente de la FETEC respectivamente) quienes habían sido acusados de los delitos de daños en propiedad ajena, golpes y amenazas:

Sumamente molesto [...] gritó que los verdaderos culpables de esos delitos eran los Padres Jesuitas, que orientaban en forma violenta al estudiantado induciéndolos a delinquir contra la propiedad ajena, contra el Régimen y contra el prójimo. Pidió, en el mismo tono, castigo para esos clérigos que lejos de practicar el amor al género humano con orientación eclesiástica, inducían a los estudiantes a matar, quemar y destruir [...] de ahí provenía la violencia. ${ }^{63}$

No obstante, otra de las actividades que implementaron los jesuitas fue la creación de la Escuela Preparatoria Popular ${ }^{64}$ que tenía el objetivo de aceptar a los alumnos rechazados de la Universidad que desde finales de los sesentas venía representando un problema serio para las autoridades locales ante la falta de oportunidades para que los jóvenes pudieran estudiar una carrera profesional. Una de las alternativas que presentó el entonces gobernador de Nuevo León, Eduardo Elizondo consistió en que "quienes puedan pagar deben hacerlo y quienes no puedan pagar, pero quieran y puedan superarse, deben recibir educación a crédito, restituyendo cuando estén en mejores condiciones económicas. No hay otro medio de poner la enseñanza superior al alcance de todo el Pueblo". ${ }^{65}$ Esta propuesta a través de la cual se intentó privatizar la educación pública fue conocida como el "Plan Elizondo". Los problemas por los que atravesaba la Universidad de Nuevo León, en ese entonces, de acurdo con el testimonio de Ruiz Cabrera, secretario general del Sindicato de Trabajadores de la

\footnotetext{
${ }^{62}$ AGN, DFS, Fondo: Jesuitas, Xavier de Obeso, Legajo: 18, Expediente: 100-17-1-68-968, 3 (14 marzo de 1969).

${ }^{63}$ AGN, DFS, Fondo: Jesuitas, Xavier de Obeso, Legajo: 22, Expediente: 100-17-1-970: 208 (18 septiembre de 1970).

${ }^{64}$ AGN, DFS, Fondo: Jesuitas, Xavier de Obeso, Legajo: 6, Expediente: 100-17-3-969: 247 (9 septiembre de 1969).

${ }^{65}$ Desplegado impreso a la opinión pública firmado por el gobernador de Nuevo León el 9 de marzo de 1968. AGN, Galería: 2, Fondo: DIPS, Caja: 1501-A, Legajo: 1: 110
} 
UANL (STUANL) y por los que se generó la lucha por la autonomía universitaria fueron tres:

[...] El económico, clásico en la Universidad. Siempre se trataba de resolverlo con el aumento de cuotas [...] Otro era el límite de cupo que dejaba a miles de estudiantes fuera de la universidad [...] el tercer problema era el marco legal [...] el gobernador tenía el pleno derecho de nombrar a los rectores y a los directores y las representaciones estudiantiles en el Consejo Universitario. ${ }^{66}$

Sin embargo, el punto más álgido ocurrió el 26 de marzo de 1971 tras la promulgación de una nueva Ley Orgánica que propugnaba la creación de una Asamblea Popular de Gobierno Universitario. Esta organización pretendía ser la máxima autoridad de la Casa de Estudios. Tenía similitudes a un Consejo de Administración en las empresas privadas de Monterrey ${ }^{67}$ Ante tales acontecimientos los estudiantes regiomontanos protestaron enérgicamente. Ruiz Cabrera recuerda que:

[...] Había tres grupos perfectamente conformados. La Juventud Comunista con un gran prestigio [...] que tenían la gran ventaja de tener una capacidad organizativa más grande que cualquier otro grupo [...] los Espartacos. Eran jóvenes estudiantes, no tan numerosos, pero tenían una gran capacidad de denuncia. Sacaban periódicos estudiantiles [...] Al lado de los Espartacos estaban los miembros de la Organización Cultural Universitaria, que eran los muchachos influidos por los jesuitas. Tenían su base en el Tec y estaba conformado por estudiantes católicos con inquietudes muy políticas. No tenían la capacidad de denuncia de los Espartacos ni la organizativa de la Juventud Comunistas, pero sí tenían una gran capacidad reflexiva; y yo recuerdo que en las asambleas que teníamos, a ellos se les escuchaba con mucha atención porque sus planteamientos eran más abarcantes para la problemática que vivíamos, y no estaban errados porque una gran parte de ellos optaron por la lucha guerrillera. ${ }^{6}$

Por tanto, el espacio universitario y la lucha por la autonomía permitieron una mayor relación y vinculación por parte de los estudiantes en problemáticas locales. El grupo de los Espartacos a raíz de estos acontecimientos, de acuerdo con Severo Iglesias se dedicó a "[...] estructurar círculos de estudio que se abocaban a discutir las bases fundamentales del marxismo-leninismo y posteriormente plantear el análisis en México como preocupación central”. ${ }^{69}$ Según el mismo testimonio “[...] la dinámica de tales espacios era muy elemental casas particulares de estudiantes donde se reunían a discutir, comentar y estudiar textos marxistas". ${ }^{70}$ Incluso algunos otros estudiantes de la UANL que se integraron a la lucha armada previamente también habían implementado y colaborado activamente en mesas redondas, conferencias y exhibición de películas o edición de revistas, algunos otros habían participado en

\footnotetext{
${ }^{66}$ Carlos Ruiz Cabrera, "La Autonomía Universitaria”, Memoria .46 (2013): 5-6.

${ }^{67}$ Óscar Flores Torres, La Autonomía Universitaria 1968-1971 (México: UANL, 2011) 117-118.

${ }^{68}$ Ruiz Cabrera, "La Autonomía” 8-9.

${ }^{69}$ Entrevista de Severo Iglesias a Héctor Torres, Nuevo León, México, 21 de mayo de 2014.

${ }^{70}$ Entrevista a Héctor Torres.
} 
programas de televisión como el Proceso a la Juventud. ${ }^{71}$ El objetivo apuntaba a tratar de concientizar al estudiantado sobre la izquierda como alternativa. ${ }^{72}$

No obstante, la participación de estudiantes católicos al igual que la presencia de sacerdotes progresistas en estos eventos fueron objeto de estrecha vigilancia por parte de la policía política y el ejército mexicano desde el momento en que se involucró al sacerdote Xavier de Obeso con el movimiento universitario. Los informes policiacos señalan que el modus operandi de los jesuitas consistía en que:

[...] a través de células se introducen en seminarios y organizaciones apostólicas, órdenes religiosas, centros pastorales, prensa y editoriales católicas donde [...] realizan una siembra de ideas que prenden admirablemente entre los católicos, por considerarlas postconciliares, siendo hasta cierto punto avanzadas, llegando a tocarse en pinzas con el marxismo. ${ }^{73}$

Por su parte, la Secretaría de la Defensa Nacional pidió al comandante de la $7^{\text {a }}$ Zona Militar en Monterrey que "[...] investigue e informe [a] este organismo [la] nacionalidad [del] Padre Jesuita Xavier de Obeso". ${ }^{74}$ La respuesta oficial señalaba que: "[...] es [de] nacionalidad mexicana y oriundo de Jalisco". ${ }^{75}$ Sin embargo, el asunto no quedó ahí, el general de división, comandante Tiburcio Garza Zamora en un informe a sus superiores reportó que:

[...] Habiéndose tenido conocimiento que el Padre Jesuita Xavier de Obeso orientaba a la juventud en contra del Gobierno, ordené que se le vigilara y se tomara nota de todo lo que dijera en contra de Nuestras Autoridades; con lo cual se le obligó al mencionado clérigo a venir a hablar con el suscrito, efectuándose una conferencia en mi oficina que duró dos horas; habiéndose grabado su contenido; y en la cual el Padre me prometió que ayudaría al Gobierno, orientando por el buen camino a la juventud e inculcándoles el respeto al gobierno actual; de lo cual me he dado cuenta que efectivamente ha estado cumpliendo con lo prometido. ${ }^{76}$

\footnotetext{
${ }^{71}$ Según los reportes policiacos el programa de televisión se efectuó el 7 de junio de 1968. La dinámica del evento, consistió en entrevistar al grupo "Federico Joliot" integrado por 13 estudiantes de la Facultad de Economía de la UNL. El programa fue definido como "izquierdista" y a los participantes como de "extrema izquierda". La transmisión se llevó a cabo de las 23 a las 24 horas. El eje rector de la emisión “[...] consistió en exponer diversas preguntas de corte político. Las más representativas fueron tres: si los partidos políticos en el país llenaban las alternativas de la juventud; si la juventud actual contemplaba el fin de los sistemas económicos del capitalismo y comunismo; y si el socialismo puede convivir con el cristianismo". Sobre este último punto el informe señala que la respuesta fue "que eran los militantes católicos o de otra religión, quienes deben ver al socialismo como una verdad política económica y social en el mundo". AGN, DIPS, Caja: 1501A, Legajo: 1: 161 (8 de junio de 1968).

${ }^{72}$ AGN, Dirección Federal de Seguridad (en adelante DFS), Fondo: José Luis Sierra: 6, (18 enero de 1972).

${ }^{73}$ AGN, DIPS, Caja: 0478, Legajo: 1, 662-663 (30 enero de 1969).

${ }^{74}$ AGN, Secretaría de la Defensa Nacional (SEDENA), Clasificación: 0729, Expediente: A/040/7: 37, (23 de noviembre de 1968).

${ }^{75}$ AGN, SEDENA, Clasificación: 0729, Expediente: A/040/7: 36 (26 de noviembre de 1968).

${ }^{76}$ AGN, SEDENA, Clasificación: 0729, Expediente: A/108.23.1: 42 (1 de noviembre de 1968).
} 
Otros reportes señalaban que, durante un encuentro de estudiantes organizado por la Central Nacional de Estudiantes Democráticos en la ciudad de Monterrey, el rancho San Ignacio de Loyola, establecimiento creado exclusivamente como retiro espiritual de los estudiantes del ITESM, fue ocupado como alberge para estudiantes universitarios de otros estados de la república. En ese espacio según los informes de la policía política:

[...] por primera vez participaron estudiantes del Instituto Tecnológico de Monterrey, por indicaciones de los Padres Jesuitas XAVIER DE OBESO y MANUEL SALVADOR RABAGO GONZALEZ, quienes anteriormente al Congreso realizaban reuniones en el Rancho de San Ignacio de Loyola, que se encuentra en Salinas Victoria, Nuevo León y que usaban para llevar a estudiantes a los llamados retiros espirituales llegando a congregar unos 1000 estudiantes y jóvenes trabajadores, quienes durante una semana permanecían en ese sitio y lo aprovechaban para prepararlos ideológicamente en sentidos de revolucionarios, para mejorar los sistemas sociales del mundo. ${ }^{77}$

Sin embargo, tras la salida de los jesuitas del ITESM, la policía política ubicó su nuevo campo de "agitación" en Monterrey vinculados a los sectores obreros de la ciudad. Se manifestaba su presencia como obreros de fábricas metalúrgicas, en la infiltración de sindicatos, colonias paupérrimas y según los reportes policiacos “[...] con el expreso fin de crear focos de agitación en dichas áreas" ${ }^{78}$ Incluso reportes de agentes locales de la DFS a sus superiores en la ciudad de México señalaban que:

En este centro de estudios [ITESM] no existe problema después de haber sido exhibido a los padres jesuitas como agitadores [...] se encuentra en esta ciudad [...] el sacerdote jesuita Xavier de Obeso. A pesar de que trata a toda costa de dignificarse asistiendo a las reuniones estudiantiles universitarias, a los mítines ferrocarrileros, con su nueva presencia personal de larga cabellera sobre los hombros y piocha a la guerrillera castrista, y darles a conocer a los activistas, que en su destierro político en Colombia y Sudamérica aprendió más teoría que les dará en una conferencia en unos días más; nadie hace caso de sus ofrecimientos. ${ }^{79}$

No obstante, su intervención en actividades como huelgas no era tan enérgica. Aunque sí tuvieron injerencia durante algunas luchas sindicales como la de la fábrica Medalla de Oro, su participaron consistió en observar o asesorar el movimiento. Sin embargo, para 1970 tras la salida de los jesuitas y de los estudiantes expulsados del Tecnológico, se buscó un nuevo campo de acción para continuar sus actividades de vinculación social entre la Iglesia y la población. El nuevo espacio fue la ciudad de Nezahualcóyotl en el Estado de México. El epicentro de los eventos fue la Iglesia del Refugio. Ahí implementaron campañas de alfabetización mediante una particular labor social con programas de desarrollo colectivo, en las cuales subyacía un interés personal. ${ }^{80}$ En realidad se trataba de un proyecto de inserción social denominado Acción Popular.

\footnotetext{
${ }^{77}$ AGN, DFS, Fondo: Liga Comunista 23 de Septiembre, Legajo 1: 432 (1974).

${ }^{78}$ AGN, DFS, Fondo: Jesuitas, Xavier de Obeso, Legajo: 1, Expediente: 12-11-73: 41 (4 julio de 1973).

${ }^{79}$ AGN, DFS, Fondo: Jesuitas, Von Bertrab, Legajo: 23, Expediente: 100-17-1-71: 161 (2 de febrero de 1971).

${ }^{80}$ AGN, DFS, Fondo: José Luis Sierra: 29 (18 de febrero de 1972).
} 
Algunos jesuitas que participaron en este proyecto como Luis del Valle señalan que “[...] se trabaja dónde y cómo parezca mejor que se sirve a todos desde los pobres, y se vive entre los pobres en habitaciones parecidas a ellos". ${ }^{81}$ Por su parte, Martín de la Rosa, ex-jesuita e iniciador del proyecto de Netzahualcóyotl refiere que aquellas actividades se desarrollaban "[...] con el proletariado (obrero, campesino, indígena, desempleado) para contribuir a la lucha revolucionaria mediante acciones de servicio al pueblo trabajador, agente principal del cambio social". ${ }^{82}$ Pero tales actividades no solo fueron monitoreadas por la DFS, se recurrió a la infiltración para la recolección de información, detectando una "conspiración del clero". En sus reportes señalaron que el grupo de jesuitas se había abocado al "control masivo de obreros, campesinos y pueblo con el pretexto de redimirlos como paso previo al control político". ${ }^{83}$ En el centro de alfabetización, los estudiantes miembros de la corporación:

[...] con el pretexto de realizar labor social promueven distintas actividades. Para los varones organizan círculos de oratoria, de periodismo, a las mujeres imparten cursos de taquigrafía, mecanografía, economía doméstica [...] En los cursos de oratoria motivan a los participantes con fotografías en las que aparecen un niño en el lodo, en otra se ve a una mujer con una cubeta implorando agua, [...] con el deliberado propósito de incitar expresiones en contra del Gobierno al que responsabilizan de todos los males. ${ }^{84}$

No obstante, a pesar de que para los jesuitas la formación educativa fue puesta en primer plano e incluso de acuerdo con Martín de la Rosa “[...] en términos generales se estudiaron las intuiciones fundamentales de Marx, rehuyeron explícitamente el dogmatismo marxista, y se sentaron las bases para una interpretación de la realidad del país y del contexto de trabajo, la marginalidad". ${ }^{85}$ Además en tales reuniones según Luis del Valle:

A veces se trataban de ponencias con su respectiva asimilación grupal, y en ocasiones eran más testimoniales. Se le pedía a algunos equipos o comunidades que narraran su situación y cómo la están juzgando y manejando. Pero fueron temas o experiencias, siempre había que situarnos en la realidad, pues continuamente estábamos con la tendencia de alejarnos de ella [...] fue siendo una instancia en la que en cada reunión se analizaba lo que está pasando en el país y en el mundo, en lo civil y en lo religioso. También suelen darse situaciones particulares que es bueno que sean conocidas por todos. A eso se le llamó Casos. También se le dedicó un tiempo a la narración y valoración de esos sucedidos a personas o grupos. ${ }^{86}$

\footnotetext{
${ }^{81}$ Luis Gordo del Valle, Siempre humanos, siempre en proceso (Aguascalientes: Centro de Estudios Jurídicos y Sociales Mispat, Centro de reflexión Teológica, Formación Cultural y Educativa, 2011) 269. Citado en Lucía Álvarez: 140.

${ }^{82}$ Martín de la Rosa Medellín, Promoción Popular y lucha de clases (análisis de caso) (México: Servicios educativos populares a.c., 1979) 10. Citado en Lucía Álvarez: 140.

${ }^{83}$ AGN, DIPS, Caja 1508-A, Expediente: 2: 5 (13 julio de 1971).

${ }^{84}$ AGN, DIPS, Caja 1508-A, Expediente: 2: 5 (13 julio de 1971).

${ }^{85}$ De la Rosa 77. Citado en Álvarez 117.

${ }^{86}$ Del Valle 123-124. Citado en Álvarez 141.
} 
Sin embargo, el elemento de mayor consideración en los trabajos por parte de los jesuitas, según la DFS, era la cooptación de prospectos para una eventual profesionalización como miembros en activo de la disidencia. Tal procedimiento se llevaba a cabo a través de un proceso de selección en tres niveles:

$1^{\circ}$ ) Los trabajos se hacen públicamente y seguros de haber captado la voluntad de varios participantes, los seleccionan. $2^{\circ}$ ) Los miembros se reúnen reservadamente $[\ldots]$ reciben cursos de capacitación, promueven discusiones sobre temas sociales siempre contra el Gobierno. Se imparten conferencias a los obreros [...] y editan periódicos pequeños que venden en los templos de esta área. Tienen formados varios grupos de obreros que inicialmente son de 10 miembros y con posterioridad integraron otros [...] Sus reuniones son presididas por cualquiera de los jesuitas o de los dos colaboradores: SIERRA y SALAS y los llaman coordinadores. Transcurridos algún tiempo seleccionan a los mejores elementos de estos grupos $[\ldots] 3^{\circ}$ ) estos grupos se convierten en secretos. En ellos se adoctrina a los miembros sobre subversión, tácticas guerrilleras y la misión que se les asigna es la toma del poder. ${ }^{87}$

Esta información policiaca tergiversa las actividades que se desarrollaban ya que de acuerdo al testimonio de Martín de la Rosa, sabemos que en realidad tales niveles hacían alusión a:

1) Un nivel amplio para el auditorio en general, abierto a cualquier colono, como las actividades pastorales y el periódico mural. 2) El segundo nivel (cuadros) suponía ya una mayor formación social y política y un compromiso serio por una lucha por el cambio social. Este grupo, más reducido que el anterior, debería ser la base para una organización futura. 3) El tercer nivel (elites) suponía ya una mayor formación social y política y un compromiso serio por una lucha por el cambio social. Este grupo, más reducido que el anterior, debería ser la base para una organización futura. ${ }^{88}$

No obstante, en la futura organización no se reivindicaba la opción armada. De acuerdo con Lucía Álvarez quien entrevistó a diversos jesuitas y recopiló algunos de los testimonios que han dejado escritos señala que "los jesuitas se declararon en contra de este tipo de acciones". ${ }^{89}$ Para ello la autora toma como evidencia el testimonio de Luis del Valle quien señala al respecto que:

Siempre defendí, con firmeza, que dadas las armas modernos no es posible lograr suplantar el poder militar del gobierno con los medios de armas que puede obtener un grupo civil. Esto repercute en la discusión misma sobre la etnicidad del movimiento armado. Es lícito el uso de las armas si es defensa, si no hay otra solución, si se prevé que se obtendrán resultados. Precisamente mi postura fue y es que por las armas no se podrán conseguir un resultado de cambio a una sociedad justa, o que al menos busque y esté en camino de la verdadera justicia. Pero me respondían que claro que se conseguiría ese

\footnotetext{
${ }^{87}$ AGN, DIPS, Caja 1508-A, Expediente: 2: 5, (13 julio de 1971).

${ }^{88}$ De la Rosa 82-83. Citado en Álvarez 121.

${ }^{89}$ Álvarez 145.
} 
resultado y se apoyaban en la teoría del foquismo: si se levantan en armas en algunos lugares, se producen focos de insurrección a los que el pueblo en su mayoría se unirá y así vendrá el cambio deseable. ${ }^{90}$

Sin embargo, el año de 1971 resultó decisivo para algunos jóvenes quienes colaboraban en el proyecto de inserción social iniciado por la comunidad de jesuitas en Netzahualcóyotl. El episodio denominado como "Jueves de Corpus" acaecido el 10 de julio de ese año en la ciudad de México al cual asistieron tanto José Luis Sierra e Ignacio Salas Obregón los impactó profundamente. Lo que había iniciado como una manifestación en apoyo a la lucha que estaba desarrollando el estudiantado regiomontano contra la Ley Orgánica de la UANL mostró de nueva cuenta el brazo represivo del régimen autoritario mexicano encabezado por Luis Echeverría Álvarez. Miguel Rico Tavera quien participó en el proyecto de los jesuitas en Netzahualcóyotl relata que:

[...] fueron José Luis [Sierra Villarreal] y Nacho [Ignacio Salas] a la marcha [...] allí hubo muertos, golpeados, y los dos llegaron esa noche a Netzahualcóyotl furiosos, pero además golpeados. Y dijeron que el cambio no puede ser posible si no es mediante las armas. Y allí empezaron el rompimiento entre ellos y los jesuitas, pero no es un rompimiento de que lárguense de aquí, es simplemente en el rompimiento en no, no estamos de acuerdo, no puede ser por aquí. ${ }^{11}$

Para estos actores sociales al igual que para muchos otros jóvenes en el país la resolución parecía contundente, no había otro camino que la autodefensa armada. Incluso algunos ex militantes del movimiento armado en Monterrey como José Luis Rhi Sausi en su texto "La parábola de la guerrilla en México" señalan a la represión del 10 de junio de 1971 como detonante de la insurrección en las principales ciudades de México. ${ }^{92}$

\section{El camino de las armas y la impronta escatológica de la LC23S}

La década de los setentas del siglo XX en México es un periodo en el que comienzan a manifestarse expresiones rebeldes en las urbes abanderadas por núcleos juveniles que cuestionaron la severidad del régimen y utilizaron las armas para combatir la represión sistemática del mismo. Las juventudes universitarias fueron el sector que nutrió en mayor medida a los grupos guerrilleros. En un primer momento, los sectores estudiantiles participaron activamente en los movimientos por democratizar las instituciones de educación superior; eventualmente trasladaron su lucha hacia el aspecto político para contribuir a implementar un triunfo gradual de sus ideas sociopolíticas. A los ojos del régimen, sus reivindicaciones pasaron por radicales; vistas a contraluz, en el mejor de los casos, solo eran reformistas, pero en gran medida

\footnotetext{
${ }^{90}$ Del Valle 269. Citado en Álvarez 145-146.

${ }^{91}$ Entrevista de Miguel Rico Tavera a Lucía Álvarez, Ciudad de México, México, 18 de marzo 2014.

92 José Luis Rhi Sausi, “La parábola de la guerrilla en México”, Coyoacán.3 (1978): 65-80.
} 
fue una generación marcada por el fuego y las bayonetas. Para un amplio sector de la clase media, los impactos del 2 de octubre de 1968 al igual que los sucesos del "Jueves de Corpus" de 1971 erosionaron las bases de legitimidad en que se sustentaba el régimen político mexicano. ${ }^{93}$ Esto formó una parte del caldo de cultivo que sacudió al sistema en la década de los setentas: los movimientos armados de guerrillas urbanas.

Una de las organizaciones político-militares más importantes en el entorno urbano fue la Liga Comunista 23 de Septiembre (LC23S) que se creó el 15 de marzo de 1973 en la ciudad de Guadalajara. El nombre alude a la Liga de los Comunistas, constituida por Carlos Marx y Federico Engels en 1848, y a la primera guerrilla socialista de la época actual en México, la que atacó el cuartel Madera el 23 de Septiembre de 1965. ${ }^{94}$ La conformación de este proyecto de guerrilla urbana fue dirigida por dos jóvenes (quienes habían tenido una participación notable en el ambiente estudiantil del entorno regiomontano): Raúl Ramos Zavala, dirigente de la Juventud Comunista en Monterrey, profesor en la Facultad de Economía de la Universidad Nacional Autónoma de México (UNAM) y creador de la agrupación de guerrilla urbana Los Procesos; e Ignacio Salas Obregón, quien provenía de una familia católica, ex estudiante del ITESM, educado por jesuitas simpatizantes de la Teología de la Liberación, ex presidente del Movimiento Estudiantil Profesional filial de la Asociación Católica de la Juventud Mexicana, fundador y dirigente de la LC23S (tras la muerte del primero en un enfrentamiento con la policía en la ciudad de México el 6 de febrero de 1972).

Para la estructuración del proyecto clandestino y armado el primer paso consistió en la creación de una Coordinación Nacional con el objeto de unificar a todos los grupos rebeldes del país. Al respecto Ramírez Salas, ex militante, señala:

El primer grupo con el que iniciaron relaciones fue el grupo de Los Guijaros, cuyos miembros provenían de la Universidad de Chihuahua y el IPN [...] Posteriormente, con los Lacandones, estudiantes chihuahuenses y del DF del IPN y de la UNAM, cuyo antecedente fue la Liga Leninista Espartaco [...] También se estableció relación con los sobrevivientes y elementos de apoyos del asalto al cuartel de ciudad Madera en 1965, que se habían reagrupado en el Movimiento Revolucionario 23 de Septiembre [...] Simultáneamente Sergio Dionisio Hirales Morán [...] estableció relaciones con la Federación de Estudiantes de Sinaloa y con el Frente Estudiantil Revolucionario (FER) de Guadalajara [...] y finalmente los Macías. ${ }^{95}$

\footnotetext{
${ }^{93}$ Héctor Aguilar Camín, A la sombra de la Revolución Mexicana (México: Cal y Arena, 1990) 222.

94 José Luis Alonso Vargas, "La guerrilla socialista contemporánea en México", Movimientos armados en México en el siglo XX, v. I. eds. Verónica Oikión, y Marta García (Morelia: Centro de Investigación y Estudios Superiores en Antropología Social/El Colegio de Michoacán, 2006) 143.

${ }^{95}$ Mario Ramírez Salas, "La relación de la Liga Comunista 23 de septiembre y el Partido de los Pobres en el estado de Guerrero en la década de los setenta", Movimientos armados en México en el siglo XX, v. II. eds. Verónica Oikión y Marta García (Morelia: Centro de Investigación y Estudios Superiores en Antropología Social/El Colegio de Michoacán, 2006) 529.
} 
El proceso de convergencia entre varios dirigentes guerrilleros que operaban en la clandestinidad, se posibilitó a través de una serie de documentos denominados "Maderas". ${ }^{96}$ A través de ellos se inició la discusión acerca de la dirección y las tareas que debía emprender la naciente organización armada cuyas resoluciones claves estribaron en la necesidad de la lucha armada en México e iniciar un proceso revolucionario colectivo. Uno de los documentos básicos sobre los planteamientos de la Liga fue escrito por Ignacio Salas, quien adoptó el seudónimo de Vicente u Oseas ${ }^{97}$ y se llamó "Las Cuestiones fundamentales sobre el movimiento armado en México". Tras establecer una Coordinadora Nacional que se sustentaba en comités regionales y locales, la LC23S durante su primer año llevó a cabo expropiaciones bancarias. Otras actividades consistieron en el "secuestro de burgueses". El primero que se propusieron realizar fue el del industrial regiomontano Eugenio Garza Sada. ${ }^{98}$ Posteriormente la Liga secuestró a otro empresario, Fernando Aranguren y al cónsul británico, Anthony Duncan Williams, en la ciudad de Guadalajara. ${ }^{99}$ No obstante al año siguiente, el 16 de enero de 1974, la LC23S decidió implementar una ofensiva insurreccional en el estado de Sinaloa que se le denominó "Asalto al Cielo". ${ }^{100}$ A raíz de todas estas actividades, los aparatos de seguridad del régimen se plantearon como objetivo fundamental la erradicación de la LC23S. Es a partir de este periodo en el que el conflicto se recrudece y los niveles de represión y brutalidad aumentaron.

Sin embargo, la LC23S pronto comprendió que la acción directa por sí sola no era suficiente para desencadenar el advenimiento revolucionario sin mencionar el incremento de las acciones represivas contra ellos a consecuencia de las mismas. Para la transformación radical de la sociedad era fundamental previamente la difusión de sus ideas. Por tal motivo el objetivo primordial, en su trabajo político, consistió en educar al proletariado y al mismo tiempo configurar las condiciones necesarias para la insurrección general. Para ello, Ignacio Salas como dirigente de la organización decidió crear un periódico de alcance nacional como eje central que a su vez cumpliera el papel de organizador colectivo. ${ }^{101}$ Es en estas latitudes donde podemos comprender

\footnotetext{
${ }^{96}$ El nombre alude al asalto del cuartel militar en Ciudad Madera, Chihuahua el 23 de septiembre de 1965 por el Grupo Popular Guerrillero. Este episodio se volvió un referente simbólico muy importante al ser considerado como el primer grupo armado socialista en el país. A partir de 1974, la Liga editó su propaganda clandestina bajo el mismo nombre como órgano central y oficial de su política revolucionaria.

${ }^{97}$ Salas Obregón utilizó el sobrenombre Óseas en referencia al profeta del Antiguo Testamento, situación que revela en buena medida su filiación religiosa.

${ }^{98}$ Esta acción se efectuó el 17 de septiembre de 1973. El operativo fue un fracaso y su desenlace terminó con la vida del empresario lo que trajo aparejadas serias repercusiones en el ámbito político ya que Garza Sada era una figura muy importante del empresariado nacional.

${ }^{99}$ Episodio acaecido el 10 de octubre de 1973. Las demandas para liberar a los dos personajes en poder de la Liga consistieron en excarcelación de militantes revolucionarios de diferentes organizaciones guerrilleras, un rescate de doscientos mil dólares y la difusión de diversos comunicados a través de los medios de comunicación. De no responder favorablemente ambos serían ejecutados. La respuesta del Estado mexicano fue negativa. Duncan Williams fue liberado, mientras que se ejecutó al empresario Aranguren.

${ }^{100}$ Esta acción tenía por objeto incentivar la guerra civil revolucionaria con estudiantes, campesinos y obreros contra las autoridades locales. El resultado no fue alentador ya que se detuvo a diversos militantes y la presencia del ejército nacional se incrementó considerablemente.

101 "Editorial", Madera 1, enero de 1974, 1.
} 
el surgimiento de su periódico, el Madera cuya producción y difusión a través de las denominadas repartizas era un deber de primer orden y sello distintivo de la militancia incluso de mayor importancia que las mismas acciones armadas. Una característica que sobresale de este periódico guerrillero estibó en su periodicidad que se mantuvo constante desde el primer ejemplar en enero de 1974 hasta el último número 58 en julio de 1981. De acuerdo con testimonios de algunos ex militantes el tiraje promedio era de entre 10 a 15 mil ejemplares. ${ }^{102}$

Las páginas del periódico Madera se caracterizaron por difundir posturas radicales y agresivas contra el régimen imperante. El énfasis estaba puesto en la ruptura con el sistema, la exaltación revolucionaria y el sacrificio del militante. En este sentido, el periodismo de Madera aportaba una actitud escatológica que desplegaba códigos morales como el sacrificio, la entrega y la devoción a la causa revolucionaria que formó parte del corpus ideológico de la LC23S y que deseaban fueran interiorizados por la militancia. Para ello, a lo largo de este periódico guerrillero se dedicaron secciones especiales para los guerrilleros caídos: muertos en enfrentamientos con la policía, asesinados o desaparecidos; acentuando sus contribuciones al movimiento revolucionario. ${ }^{103}$ La glorificación de los combatientes revolucionarios quienes habían sacrificado su vida por los oprimidos y el advenimiento de un mundo mejor a través de su "justa lucha" a manos de los explotadores burgueses y el régimen represor se publicaban de manera constante en forma de homenajes en el Madera. Es plausible que estas publicaciones ayudaran a preparar a los militantes y futuros reclutas para la vida clandestina y la lucha armada, que implicaban la posibilidad de perder la vida.

Así los asesinatos y desapariciones contra los revolucionarios, esos "hechos de crueldad" como ellos mismos los refieren, eran constantemente denunciados en el periódico con una finalidad muy particular: mostrar el verdadero rostro de la burguesía y señalar que la represión se desbordaba y generalizaba en "detenciones y torturas de familiares, simpatizantes, amigos y hasta simples conocidos de los militantes de la Liga"104 lo que a su vez, en ediciones posteriores, les permitiría evidenciar "las funciones del Estado burgués como máquina opresora". ${ }^{105}$ A través de las páginas del Madera es posible analizar una retórica de la muerte mediante la cual proyectaban una presencia simbólica y positiva sobre la misma. Por ejemplo, en el Madera No. 14 (septiembre de 1975) en una noticia acerca de las muertes de "Mariano" y "Alejandra" acaecida el 15 de junio de 1975 en terrenos de la UNAM, denunciaban el hecho como "asesinatos a sangre fría llevados a cabo por los perros burgueses". ${ }^{106}$ El abordaje desplegado no solo desmontaba la versión oficial que los

\footnotetext{
${ }^{102}$ Mauricio Abraham Laguna Berber, "La prensa clandestina en México. El caso del periódico Madera, 1973-1981" (Tesis, Licenciatura en Ciencias de la Comunicación, Universidad Nacional Autónoma de México, 1997) 111-114.

${ }^{103}$ Lucio Rangel Hernández, "La Liga Comunista 23 de Septiembre 1973-1981. Historia de la Organización y sus militantes” (Tesis, Doctorado en Historia, Universidad Michoacana de San Nicolás Hidalgo, 2011) 141.

104 “El sello sangriento al informe presidencial”, Madera 32, septiembre de 1977, 9.

105 "Acerca de las declaraciones del procurador Óscar Flores Sánchez sobre los revolucionarios 'desaparecidos'", Madera 40, marzo de 1979, 4.

106 "Ni cárceles, ni masacres nos desviaran del camino revolucionario ¡Viva la revolución comunista!”,
} 
relegaba como criminales sino que señalaban que ellos "aun después de su muerte estarán impulsando el desarrollo del movimiento revolucionario". ${ }^{107}$ Estas acciones (asesinatos de militantes) solo podían servir, desde la perspectiva de la LC23S para:

[...] inyectar a los revolucionarios una mayor energía, una mayor decisión, una mayor combatividad en el desarrollo de la lucha revolucionaria. Con sus acciones revolucionaras, siembran el sendero rojo de la Guerra Civil Revolucionaria y su sangre, unida a la de tantos camaradas caídos, abona el grandioso escenario de la Revolución Socialista. ${ }^{108}$

De tal manera la muerte física de los militantes, en clave sacrificial, “[ ... no inspira llanto o temor $[\ldots]$ inspira fervor revolucionario, nos imbuye un profundo odio de clase [...] ha atizado el fuego sagrado de la revolución en nuestros pechos". En la parte final, el artículo afirma que: "los revolucionarios vamos adelante, el abismo no nos detiene, el agua es más bella desempeñándose, si morimos, moriremos como soles; despidiendo luz". ${ }^{109}$ Por último, el periódico mantendría una denuncia constante hasta su último ejemplar en julio de 1981 en el que, en dedicatoria a Ignacio Salas Obregón líder histórico de la agrupación, capturado por la policía política tras un enfrentamiento el 24 de abril de $1974,{ }^{110}$ publicaron:
CAMARADA: DONDE QUIERA QUE ESTÉS, SUFRIENDO EL SUPLICIO DEL POTRO BURGUÉS, EN LA MAZMORRA CLANDESTINA O EN CUALQUIER PARTE QUE TE TENGA LA TIRANÍA BURGUESA, RECIBE EL MÁS FERVIENTE HOMENAJE DE TODOS LOS PROLETARIOS Y DE NUESTRA PARTE, EL COMPROMISO DE REDOBLAR ESFUERZOS PARA CONTINUAR LA LUCHA REVOLUCIONARIA. ${ }^{111}$

Por tanto, si consideramos la forma en que son representados los guerrilleros en el Madera se puede advertir que el sentido de la muerte para la LC23S encarna una presencia positiva que incidió en la construcción de su obra revolucionaria. Ejemplo de ello son los llamados a la militancia, “'Camaradas: al morir nacen; porque la bestia burguesa al pretender eliminarlos, los inmortaliza gloriosamente en la historia!" 112 De tal manera, el periódico Madera dotó a los revolucionarios de una actitud escatológica en la cual la glorificación de los militantes capturados, el homenaje ritual a sus muertos, la exaltación sacrificial de dar la vida por la causa contribuyó a generar modelos formadores a través de los cuales se preparaba a los militantes en un combate en donde iba la vida de por medio, bajo la convicción de que su muerte ayudaría a la construcción de una nueva sociedad en la cual sería efectiva la redención social de los oprimidos gracias a la continuidad de otros combatientes.

\footnotetext{
Madera 14, septiembre de 1975: 12.

${ }^{107}$ Madera 14: 13.

${ }^{108}$ Madera 14: 15 .

${ }^{109}$ Madera 14: 15.

${ }^{110}$ AGN, DFS, Fondo: Liga Comunista 23 de Septiembre, Legajo: 2: 272 (1974).

111 “Oseas. Semblanza del dirigente revolucionario", Madera 58, julio de 1981: 17.

112 "Por los compañeros caídos", Madera 58, julio de 1981: 20.
} 


\section{Conclusiones}

A lo largo de este trabajo se ha mostrado que la incorporación de los jesuitas en el espacio universitario del entorno regiomontano durante la segunda mitad del siglo XX fue un factor clave en la politización estudiantil. Como maestros del ITESM estos clérigos postulaban la Teología de la Liberación y en función de ella, inculcaron una nueva directriz de la explicación de la doctrina cristiana al enfatizar la necesidad de intervención de la Iglesia en problemáticas sociales. La investigación permite especificar y señalar las principales actividades que desarrollaron los sacerdotes ignacianos, las cuales no solo se restringieron a las aulas universitarias, sus acciones fueron más allá de las mismas y se desplegaron a través del Movimiento Estudiantil Profesional (MEP) al igual que la Organización Cultural Universitaria (OCU) y se posibilita examinar algunas de las características distintivas de ellas. A grandes rasgos estas instancias y las dinámicas sociales que generaban permitieron la interacción y vinculación de jóvenes católicos con personajes provenientes de organismos de izquierda como la Juventud Comunista. No obstante, los cambios de orientación en la Compañía de Jesús y su preferencia por los oprimidos implicaron rupturas con el proyecto educativo del ITESM y de igual manera conllevó que sus diversas actividades fueran consignadas como "subversivas" por los aparatos de inteligencia del régimen político mexicano motivo por el cual fueron vigiladas e infiltradas, detectando una "conspiración del clero", al punto incluso que en diversos informes los señalaba como determinantes en la organización armada de la Liga Comunista 23 de Septiembre. Sin embargo al ser contrastados con testimonios orales y escritos de algunos sacerdotes jesuitas se ha comprobado que, en gran medida, la información recopilada por los reportes policiacos era proclive a exagerar y tergiversar la actuación de los clérigos ignacianos con el objetivo de enfatizar su peligrosidad como "promotores de la justa violencia" a pesar de que ninguno de ellos se sumó al proyecto guerrillero y continuarían su labor de inserción social con el proyecto de Acción Popular en la ciudad de Netzahualcóyotl (Estado de México).

En esta tesitura, el año de 1971 resultó crucial para algunos jóvenes que colaboraban con la Compañía de Jesús en el proyecto antes mencionado. La masacre del "Jueves de Corpus" acaecida el 10 de junio de ese año en la cual participaron tanto Ignacio Salas Obregón y José Luis Sierra Villarreal aunada a la represión del 2 de octubre de 1968 en Tlatelolco confirmó para estos actores (al igual que para un considerable sector de la clase media) la necesidad de la autodefensa armada lo cual implicó un rompimiento con la comunidad de sacerdotes jesuitas quienes se declararon en contra de este tipo de acciones. No obstante, a pesar de que ninguno de los jesuitas se incorporó al proyecto armado la impronta que dejaron en algunos jóvenes fue profunda. Tal fue el caso de Ignacio Salas Obregón quien se abocó a la conformación de una de las organizaciones de guerrilla urbana más importante de la década de los setentas en México la Liga Comunista 23 de Septiembre y vislumbró la creación de su periódico oficial, el Madera. Este periódico guerrillero de alcance nacional aportó a los militantes una actitud escatológica con respecto al sacrificio por los oprimidos, por la causa y desplegó una presencia positiva sobre la muerte, en clave sacrificial, que incidió en la construcción de su obra revolucionaria y que formó parte del corpus ideológico de esta agrupación armada. 
La influencia jesuita en la conformación de la Liga Comunista 23 de Septiembre...

\section{Bibliografía}

\section{Fuentes Primarias}

\section{Archivos}

Archivo General de la Nación (AGN)

Galería 1: Dirección Federal de Seguridad (DFS)

Galería 2: Dirección de Investigaciones Políticas y Sociales (DIPS)

Archivo de la Secretaría de la Defensa Nacional (SEDENA)

Instituto Tecnológico de Estudios Superiores de Monterrey (ITESM): Boletín de Información 1966-1968.

\section{Publicaciones periódicas}

El Heraldo de México (Ciudad de México) 1971, 1972.

El Norte (Monterrey) 1972.

Excélsior (Ciudad de México) 1972.

Madera (México) 1974, 1975 1977, 1979, 1981.

\section{Entrevistas}

Flores Olivo, Juan Carlos, entrevista realizara por Lucía Álvarez, México, 17 de junio 2014.

González Severo, Iglesia, entrevista realizara por Torres, Héctor. México 21 de junio de 2014.

Rico Tavera, Miguel, entrevista realizara por Lucía Álvarez, México, 18 de marzo 2014.

Viejo, Héctor, entrevista realizara por Lucía Álvarez, México, 19 de junio de 2014. 


\section{Fuentes secundarias}

\section{Libros}

Aguilar Camín, Héctor. A la sombra de la Revolución Mexicana. México: Cal y Arena, 1990.

Blancarte, Roberto. Historia de la Iglesia católica en México. México: Fondo de Cultura Económica, 1992.

Brieza, Hernán. Camilo Torres. Sacristán de la Guerrilla. Buenos Aires: Capital Intelectual, 2007.

Carr, Barry. La izquierda mexicana a través del siglo XX. México: Era, 2000.

Flores Torres, Óscar. La Autonomía Universitaria 1968-1971. México: UANL, 2011.

Gabriel Muro, Víctor. Iglesia y movimientos sociales. México: Colegio de Michoacán, 1994.

Gaspar, Gabriel. Guerrillas en América Latina. Chile: FLACSO, 1997.

Gómez Junco, Horacio. Desde Adentro. Monterrey: Gobierno del Estado de Nuevo León, 1997.

Gordo del Valle, Luis. Siempre humanos, siempre en proceso. Aguascalientes: Centro de Estudios Jurídicos y Sociales Mispat, Centro de reflexión Teológica, Formación Cultural y Educativa, 2011.

Matilde Ollier, María. El fenómeno insurreccional y la cultura política 1969-1973. Buenos Aires: Centro Editor de América Latina, 1986.

Mendirichaga, Rodrigo. El Tecnológico de Monterrey. México: Castillo, 1982.

Monroy, Juan Antonio. Un enfoque evangélico a la Teología de la Liberación. Barcelona: Libros Clie, 1991.

Montemayor Hernández, Andrés. Historia de Monterrey. México: Asociación de Editores y Libreros de Monterrey, 1971.

Nercesian, Inés. La política en armas y las armas de la política: Brasil, Chile y Uruguay 1950-1979. Buenos Aires: CLACSO, 2013.

Rosa Medellín, Martín de la. Promoción Popular y lucha de clases (análisis de caso. México: Servicios educativos populares a.c., 1979. 
La influencia jesuita en la conformación de la Liga Comunista 23 de Septiembre...

Saranyana, Josep-Ignasi. Cien años de Teología en América Latina, 1899-2001. Bogotá: Consejo Episcopal Latinoamericano, 2005.

Solís, Patricio. Inequidad y movilidad social en Monterrey. México: Colegio de México, 2007.

Sols, José. La teología histórica de Ignacio Ellacuría. Madrid: Trotta, 1999.

Von Bertrab, Hermann. Hacia la puerta en búsqueda del destino. México: Castellanos Editores, 2004.

\section{Capítulos de libros}

Alonso Vargas, José Luis. "La guerrilla socialista contemporánea en México". Movimientos armados en México en el siglo XX, v. I. Eds. Verónica Oikión y Marta García. Morelia: Centro de Investigación y Estudios Superiores en Antropología Social/El Colegio de Michoacán, 2006.

Concha, Miguel. "Teología de la Liberación”. Diccionario de Política, t. 2. Bobbio, Norberto et al. México: Siglo XXI, 1999.

Crespo, Horacio. "Una hermenéutica comprensiva de la radicalización cristiana en los sesenta". Cristianismo y Revolución. Los orígenes intelectuales de la guerrilla argentina. Gustavo Morello. Argentina: Universidad Católica de Córdoba, 2003.

Flores, Óscar. "Del Movimiento Universitario a la Guerrilla. El caso de Monterrey 1968-1973". Movimientos armados en México en el siglo XX, v. II. Eds. Verónica Oikión y Marta García. Morelia: Centro de Investigación y Estudios Superiores en Antropología Social/El Colegio de Michoacán, 2006.

Gutiérrez, Alberto. "Arrupe y América Latina”. Pedro Arrupe, General de la Compañia de Jesús. Nuevas aportaciones a su biografía. Ed. Gianni la Bella. España: Mensajero y Sal Terrae, 2007.

Melgar Bao, Ricardo. "La memoria sumergida. Martirologio y sacralización de la violencia en las guerrillas latinoamericanas". Movimientos armados en México en el siglo XX, v. I. Eds. Verónica Oikión y Marta García. Morelia: Centro de Investigación y Estudios Superiores en Antropología Social/El Colegio de Michoacán, 2006.

Ramírez Salas, Mario. "La relación de la Liga Comunista 23 de Septiembre y el Partido de los Pobres en el estado de Guerrero en la década de los setenta". Movimientos armados en México en el siglo XX, v. II. Eds. Verónica Oikión y Marta García. Morelia: Centro de Investigación y Estudios Superiores en Antropología Social/El Colegio de Michoacán, 2006. 
Rojas, Javier y María Elena Rodríguez. "La industria siderúrgica en Monterrey HyLSA (1943-1985)". Monterrey siete estudios contemporáneos. Ed. Mario Cerutti. México: UANL, 1988.

Vellinga, Menno. "Crecimiento económico y distribución del ingreso en Monterrey". Monterrey siete estudios contemporáneos. Ed. Mario Cerutti. México: UANL, 1988.

Vidales, Raúl. "Periodización de la historia de la Iglesia en México (1968-1983)". La participación de los cristianos en el proceso popular de liberación en México. Coord. Pablo Casanova. México: Siglo XXI, 1986.

\section{Artículos de revistas}

Beltrán del Río, Pascal. "El caso del fundador de la Liga 23 de Septiembre, ante la Fiscalía Especial”. Proceso. 1320 (2002): 24-27.

González, Fernando. “Algunos grupos radicales de izquierda y de derecha con influencia católica en México (1965-1975)”. Historia y Grafía .29 (2007): 57-93.

Levine, Daniel. "Camilo Torres: fe, política y violencia". Sociedad y Religión 21. 34/35 (2011): 59-91.

Martínez Morales, Darío. "Camilo Torres Restrepo: cristianismo y violencia". Theologica Xaveriana 61.171 (2011): 131-167.

Rhi Sausi, José Luis. “La parábola de la guerrilla en México". Coyoacán.3 (1978): 65-80.

Ruiz Cabrera, Carlos. "La Autonomía Universitaria”. Memoria.46 (2013): 3-11.

Tesis, ponencias, documentos y otros Inéditos

Álvarez Gutiérrez, Ana Lucía. "De Católico a Guerrillero: el caso de Ignacio Salas Obregón". Tesis inédita de Licenciatura en Historia, Universidad de Guanajuato, 2015.

Domínguez Rueda, Fortino. "Católicos en la guerrilla mexicana de los setenta. El caso de la Liga Comunista 23 de Septiembre". Tesis inédita de Licenciatura en Historia, Universidad de Guadalajara, 2006.

García Piera, María de los Dolores. "Surgimiento y expansión del Instituto Tecnológico y de Estudios Superiores de Monterrey". Tesis inédita de Maestría en Historia, Universidad Iberoamericana, 2008. 
La influencia jesuita en la conformación de la Liga Comunista 23 de Septiembre...

Laguna Berber, Mauricio Abraham. "La prensa clandestina en México. El caso del periódico Madera, 1973-1981". Tesis inédita de Licenciatura en Ciencias de la Comunicación, Universidad Nacional Autónoma de México, 1997.

Rangel Hernández, Lucio. "La Liga Comunista 23 de Septiembre 1973-1981. Historia de la Organización y sus militantes". Tesis inédita de Doctorado en Historia, Universidad Michoacana de San Nicolás Hidalgo, 2011.

\section{Publicaciones en Internet}

https://nsarchive2.gwu.edu//NSAEBB/NSAEBB180/070-Grupos\%20armados.pdf (2006). 